THE value of CD30 and the soluble circulating fragment of CD30 (sCD30) for atopic dermatitis (AD) remains unclear. In particular, little is known about the effects of age, duration of disease and Scoring Atopic Dermatitis index (SCORAD) on the levels of serum SCD30 in patients affected by AD.

In the present study, we have analysed serum SCD30 levels of adult patients affected by AD. The study's population includes 18 non-smoking outpatients, with a diagnosis of AD. As a control group we studied 18 non-atopic subjects from laboratory staff, matched for sex and age. These subjects had no history of AD, urticaria or seasonal or perennial rhinitis or asthma, and had negative skin prick test to a panel of allergens.

The SCD30 serum levels were clearly higher in patients affected by AD $(14.2 \pm 9.0 \mathrm{IU} / \mathrm{ml})$ than in healthy subjects $(1.2 \pm 0.8 \mathrm{IU} / \mathrm{ml})(p<0.001)$. No differences were observed between males and females affected by atopic dermatitis, regarding age, duration of disease and SCORAD. Significant correlations were found between serum levels of SCD30 levels and age $(r=-0.55 ; 95 \%$ confidence interval (CI) for $r$ (Fisher's $z$ transformed) $=-0.81$ to -0.12 ; $p=0.01)$, duration of the disease (months) $(r=-$ 0.64; 95\% CI for $r$ (Fisher's $z$ transformed) $=-0.85$ to $-0.24 ; p=0.004)$ and SCORAD $(r=-0.74 ; 95 \% \mathrm{CI}$ for $r$ (Fisher's $z$ transformed $)=-0.89$ to $-0.42 ; p=$ 0.004).

As demonstrated by the close correlation with age, duration of disease and SCORAD, serum levels of sCD30 appear to be an additional marker for the follow-up of $\mathrm{AD}$.

Key words: Atopic dermatitis, Serum sCD30, SCORAD

\section{Serum levels of soluble CD30 in adult patients affected by atopic dermatitis and its relation to age, duration of disease and Scoring Atopic Dermatitis index}

\author{
Gabriele Di Lorenzo', Sebastiano Gangemi ${ }^{2}$, \\ Rosaria Alba Merendino ${ }^{2}$, Paola Lucia Minciullo², \\ Serafina Paola Cannavò ${ }^{3}$, Nicola Martinelli ${ }^{4}$, \\ Pasquale Mansueto ${ }^{1}$, Giovanni Battista Rini ${ }^{1}$, \\ Roberto Corrocher ${ }^{4}$ and Maria Luisa Pacor ${ }^{4, C A}$
}

${ }^{1}$ Dipartimento di Medicina Clinica e delle Patologie Emergenti, Università degli Studi di Palermo, Italy; ${ }^{2}$ Dipartimento di Patologia Umana, Università degli Studi di Messina, Italy; ${ }^{3}$ Dipartimento di Medicina Sociale Territoriale, Università degli Studi di Messina, Italy ${ }^{4}$ Dipartimento di Medicina Clinica e Sperimentale, Università degli Studi di Verona, Sezione B - Policlinico GB Rossi, Piazzale Scuro 10, 37134 Verona, Italy

\author{
${ }^{\mathrm{CA}}$ Corresponding author \\ Fax: + 3945580111 \\ E-mail: marialuisa.pacor@univr.it
}

\section{Introduction}

CD30 is a member of the tumour necrosis factornerve growth factor (TNF-NGF) receptor superfamily existent as a membrane glycoprotein of 105 and 120 $\mathrm{kDa}$, derived from a $90 \mathrm{kDa}$ precursor, and a $57 \mathrm{kDa}$ intracellular form. CD30 is considered a marker of activated $\mathrm{T}$ helper (Th)0/Th2 lymphocytes, which are key cells in the pathogenesis of allergic diseases. ${ }^{1}$ However, in some diseases with a predominance of Th1 cells (i.e. in rheumatoid arthritis), there is also a presence of CD30 $+\mathrm{T}_{\text {cells. }}{ }^{2}$ The membrane molecule can be transformed into a soluble form (sCD30) by limited proteolysis (i.e. shedding) as well as the cytokine receptors, and then can be detected in biological fluids, including serum. ${ }^{1}$

Atopic dermatitis (AD) is a skin disorder that arises as a result of the interaction of environmental factors with an abnormal immune system in a genetically predisposed individual. $^{3}$

Immunological defects in both humoral and cellular response are present in $\mathrm{AD}^{3}$ Indeed, it is possible to find high amounts of immunoglobulin $\mathrm{E}$, eosinophil cationic protein, soluble interleukin (IL)-2 receptor, soluble CD23 and some adhesion molecules in sera of patients affected by AD., ${ }^{4,5}$ Recently, studies on eczematous skin diseases, such as $\mathrm{AD}$, have focused on T-cell-mediated immune effector mechanisms. ${ }^{6}$ The abnormalities in cytokine production typical of $\mathrm{AD}$ are linked to an imbalance between Th1 and Th2 cells. ${ }^{3}$ Indeed, high levels of Th2-type cytokines, such as IL-4 and IL-5, are produced by $\mathrm{T}$ cells that are isolated from skin biopsies and are found in the supernatant of peripheral blood lymphocytes. ${ }^{7}$ On the other hand, interferon (IFN) $-\gamma$ is less produced by $\mathrm{T}$ cells of patients with severe $\mathrm{AD}$ than by $\mathrm{T}$ cells from healthy donors. This deficiency of IFN- $\gamma$ is not restored by IL-2, IL-15 and IL-18. ${ }^{8}$

Allergen-reactive Th0/Th2-like cells expressing membrane CD30 are present in the circulation of $\mathrm{AD}$ patients. Moreover, in patients affected by $\mathrm{AD}$, it is possible to find $\mathrm{CD} 30+\mathrm{T}$ cells and high sCD30 levels are present in the serum of atopic patients. 
However, recent data have shown that the T-cell-line unstimulated cultures of patients with $\mathrm{AD}$ expressed a Th1 profile. After stimulation with anti-CD3 and anti-CD28 monoclonal antibodies, the cytokine expression showed rapid initial up-regulation of Th2 followed by a Th1 profile. Therefore, skin T lymphocytes from $\mathrm{AD}$ patients seem to consist of a heterogeneous population of Th1 and Th2 or Th0 cells. ${ }^{10}$ Moreover, work by Tanaka, using in situ hybridisation, elucidated mRNA expressions of both Th1 and Th2 cytokine in the lesions of AD. ${ }^{11}$

In the present study, we have analysed serum sCD30 levels in adult patients affected by AD and its relation to age, duration of disease, and Scoring Atopic Dermatitis index (SCORAD).

\section{Materials and methods}

A group of 18 non-smoking outpatients (nine males and nine females; aged 13-39 years; mean age, $23.8 \pm 8.6$ years) with clinical diagnosis of $\mathrm{AD}$ has been studied. At the time of the study, none of patients was receiving steroid or immunosuppressants. The severity of dermatitis was evaluated according to SCORAD. ${ }^{12}$ Briefly, SCORAD defines a score for three parameters: extent, intensity and subjective symptoms. The extent of the lesions is calculated with the rule of nines and indicates the body surface involved. Intensity items are erythema, oedema/papulation, oozing/crusts, excoriations, lichenification and dryness of non-involved skin (0-3 points for each item). Subjective symptoms are itching and sleep loss $(0-10$ points for each item). The total score is calculated according to the following equation: SCORAD $=(0.2 \times$ area $)+$ $[3.5 \times($ eritema + oedema/papulation + oozing/crusts + excoriations + lichenification + dry skin $)]+$ subjective score. Index scores of disease's severity range from 0 to 103 .

As a control group we studied 18 non-atopic subjects from laboratory staff (10 males and eight females; aged 18-41 years; mean age, 25.1 \pm 7.9 years). They had no history of $\mathrm{AD}$, seasonal or perennial rhinitis, asthma, or urticaria, and had negative skin prick test to a panel of allergens. Blood samples were draw in Vacutainer SST tubes and, after allowing clotting for $60 \mathrm{~min}$ at room temperature, the blood was centrifuged at $1300 \times g$ for $10 \mathrm{~min}$ at room temperature. The sera were frozen at $-70^{\circ} \mathrm{C}$ and analysed at the end of the study period.

Serum sCD30 levels were measured by a sandwich enzyme-linked immunoassay CD30 (Dako, Milan, Italy). The assay was performed according to the manufacturer's instruction and expressed as international units per millilitre. The detection limit of the assay was $1 \mathrm{IU} / \mathrm{ml}$.
Data were expressed as the mean \pm standard deviation. An unpaired $t$-test was used to compare the difference between the groups. Simple regression analysis was used to assess the correlation between serum sCD30 levels and age, duration of disease and SCORAD.

\section{Results}

Serum levels of sCD30 in patients affected by AD $(14.2 \pm 2.1 \mathrm{U} / \mathrm{ml})$ were significantly higher than those observed in healthy subjects (versus $1.1 \pm 0.2 \mathrm{IU} / \mathrm{ml}$ ) $(p<0.001)$. No significant age-dependent influence on the serum sCD30 levels was observed in patients and in the control set (data not shown).

No differences between males and females affected by $\mathrm{AD}$ were found for age, duration of the disease, SCORAD and levels of serum sCD30 (Table 1).

As shown in Fig. $1 \mathrm{~A}-\mathrm{C}$, significant correlations were found between serum levels of sCD30 levels and age $(r=-0.55 ; 95 \%$ confidence interval for $r$ (Fisher's $z$ transformed) $=-0.81$ to $-0.12 ; p=0.01$ ), duration of the disease (months) $(r=-0.64 ; 95 \% \mathrm{CI}$ for $r$ (Fisher's $z$ transformed) $=-0.85$ to $-0.24 ; p=$ 0.004), and SCORAD ( $r=-0.74 ; 95 \%$ CI for $r$ (Fisher's $z$ transformed) $=-0.89$ to $-0.42 ; p=0.004)$.

\section{Discussion}

$\mathrm{AD}$ is a chronic allergic inflammatory disease that manifests itself as eczematous skin lesions. ${ }^{3}$ Both Th1 and Th2 cells are involved in AD. A recent study suggested that the relative contribution of Th1-type and Th2-type cytokines to the pathogenesis of AD depends on the duration of the eruption. ${ }^{3}$ It has been demonstrated, by in situ hybridization, that acute skin lesions had larger numbers of cells that were positive for IL-4, IL-5, and IL-13 mRNA, whereas they contained few IFN- $\gamma$-positive cells, compared with normal control skin. ${ }^{13}$ Comparing acute AD with chronic AD skin lesion revealed significantly lower number of IL-4 and IL-13 mRNA-positive cells but increased numbers of IL- 5 and IFN- $\gamma$-positive cells. Other studies confirmed that an increased in situ expression of Th2-type cytokines IL-4 and IL-10 was always observed together with increased expression of Th1-type cytokine IFN- $\gamma$ within identical chronic

Table 1. Comparison between males and females affected by $A D$

\begin{tabular}{lccc}
\hline & Males $(n=9)$ & Females $(n=9)$ & $p$ \\
\hline Age (years) & $23.7 \pm 7.8$ & $24.0 \pm 9.8$ & 0.9 \\
Onset of AD (months) & $186.6 \pm 95.5$ & $126.5 \pm 86.6$ & 0.1 \\
SCORAD index & $36.7 \pm 14.4$ & $32.7 \pm 14.5$ & 0.6 \\
Serum sCD30 & $11.0 \pm 8.3$ & $17.3 \pm 8.9$ & 0.1 \\
\hline
\end{tabular}



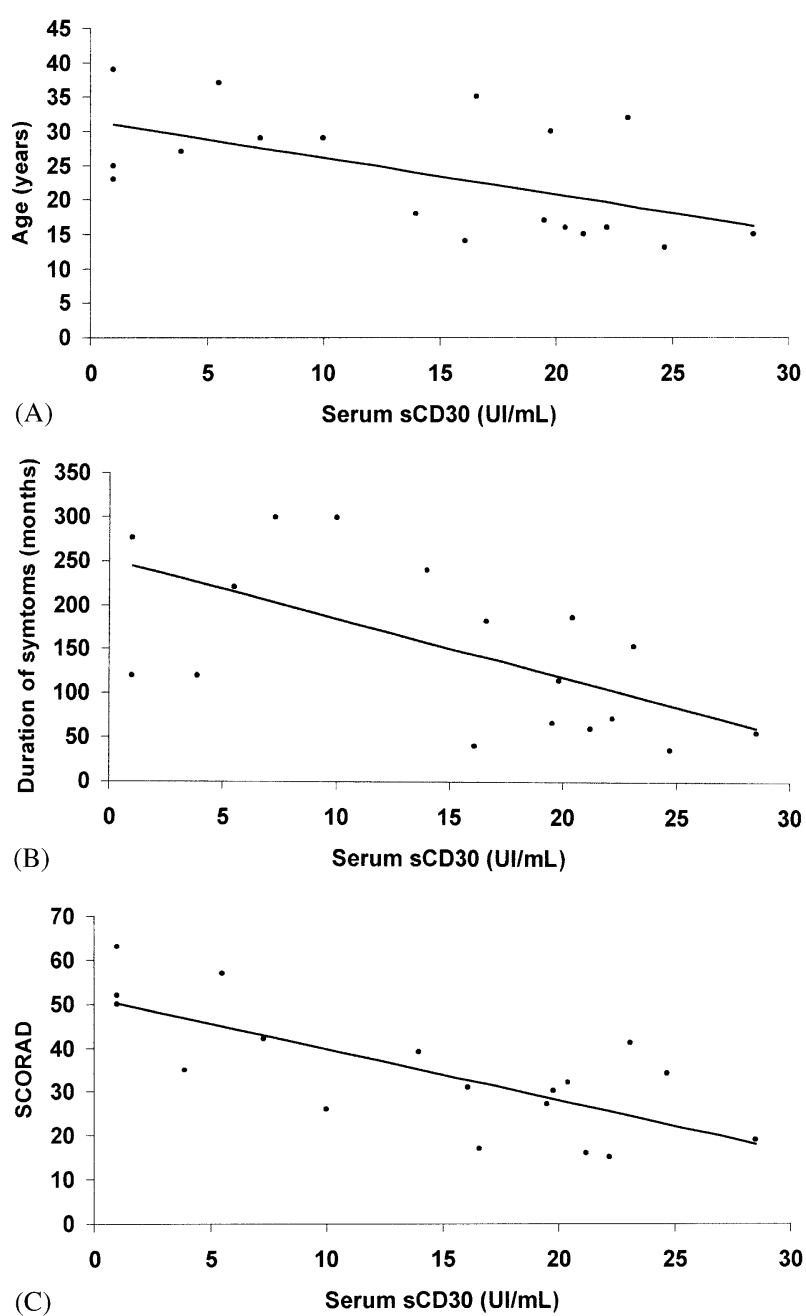

FIG. 1. (A) Correlation between serum sCD30 and age (years) $(r=-0.55 ; 95 \% \mathrm{Cl}$ for $r$ (Fisher's $z$ transformed $)=-0.81$ to $0.12 ; p=0.01$ ). (B) Correlation between serum sCD30 and duration of disease (months) $(r=-0.64 ; 95 \% \mathrm{Cl}$ for $r$ (Fisher's $z$ transformed) $=-0.85$ to $-0.24 ; p=0.004)$. (C) Correlation between serum sCD30 and SCORAD $(r=-0.74 ; 95 \% \mathrm{Cl}$ for $r$ (Fisher's $z$ transformed) $=-0.89$ to $-0.42 ; p=0.004$ ).

skin lesions of the same patients. ${ }^{14,15}$ These findings indicate that in the acute phase $\mathrm{AD}$ is driven by Th2 cells, while in the chronic phase AD is driven by both Th1 and Th2 cells. We found significantly higher levels of sCD30 in serum obtained from AD patients compared with healthy non-atopic controls. The most important finding of this study was that serum sCD30 levels are negatively correlated with age and duration of disease. It is therefore suggested that the chronic phase of AD is associated with down-regulation of Th2 cells. This implies that the highest SCORAD are related to a down-regulation Th2 cells.

In conclusion, the present data are consistent with the hypothesis that chronic $\mathrm{AD}$ is predominantly driven by activated Th1 cells and the aggravation of $\mathrm{AD}$ is accompanied by up-activation of Th2 cells. Serum sCD30 may be a useful circulating marker as far as the choice of the treatment of $\mathrm{AD}$ is concerned.

ACKNOWLEDGEMENTS. This work was supported in part by a grant (60\%) from MIUR (Italy) to Gabriele Di Lorenzo, Roberto Corrocher and Rosaria Alba Merendino.

\section{References}

1. D'Elios mm, Romagnani P, Scaletti C, et al. In vivo CD30 expression in human disease with predominant activation of Th2-like T cells. J Leukoc Biol 1997; 61: 539-544.

2. Gerli R, Lunardi C, Vinante $F$, Bistoni $O$, Pizzolo G, Pitzalis C. Role of $\mathrm{CD} 30+\mathrm{T}$ cells in rheumatoid arthritis: a counter-regulatory paradigm for Th1-driven diseases. Trends Immunol 2001; 22: 72-77.

3. Leung DY. Pathogenesis of atopic dermatitis. J Allergy Clin Immunol 1999; 104: S99-S108.

4. Kagi MK, Joller-Jemelka H, Wuthrich B. Correlation of eosinophils, eosinophil cationic protein and soluble interleukin-2 receptor with the clinical activity of atopic dermatitis. Dermatology 1992; 185: 88-92.

5. Sanchez-Guerrero I, Albaladejo MD, Garcia-Alonso AM, Muro M, Hernandez J, Alvarez MR. Solubile CD23 (sCD23) serum levels and lymphocyte subpopulations in asthma. Allergy 1994; 49: 587-592.

6. Trautmann A, Akdis M, Broker EB, Blaser K, Akdis CA. New insights into the role of $\mathrm{T}$ cells in atopic dermatitis and allergic contact dermatitis. Trends Immunol 2001; 22: 530-532.

7. Kagi MK, Wuthrich B, Montano E, Barandun J, Blaser K, Walker C. Differential cytokine profiles in peripheral blood lymphocytes supernatants and skin biopsies from patients with different forms of atopic dermatitis, psoriasis and normal individuals. Int Arch Allergy Immunol 1994; 103: 332-340.

8. Jung T, Witzak K, Dieckhoff K, Zachmann K, Heidrich S, Aversa G, Neumann C. IFN-gamma is only partially restored by co-stimulation with IL-12, Il-2, Il-15, IL-18 or engagement of CD28. Clin Exp Allergy 1999; 29: $207-216$.

9. Caproni M, Salvatore E, Cardinali C, Brazzini B, Fabbri P. Solubile CD30 and cyclosporine in severe atopic dermatitis. Int Arch Allergy Immunol 2000; 12: $324-328$

10. Higashi N, Bang K, Gesser B, Lund M, Thestrup-Pedersen K. Cytokine expression of skin T-lymphocytes from patients with atopic dermatitis. Acta Derm Venereol 2001; 81: 3-7.

11. Tanaka Y. Pathogenesis and guidelines for therapy of atopic dermatitis. Nippon Rinsho 2001; 59: 1219-1227.

12. Severity scoring of atopic dermatitis: the SCORAD Index. Consensus report of the European Task Force on atopic dermatitis. Dermatology 1993; 186: $23-31$

13. Hamid Q, Boguniewicz M, Leung DY. Differential in situ cytokine expression in acute versus chronic atopic dermatitis. J Clin Invest 1994; 94: $870-876$.

14. Grewe M, Gyufko K, Schopf E, Krutman J. Lesional expression of interferon-gamma in atopic eczema. Lancet 1994; 343: 25-26.

15. Ohmen JD, Hanifin JM, Nickoloff BJ, et al. Overexpression of IL-10 in atopic dermatitis. Contrasting cytokine patterns with delayed-type hypersensitivity reactions. J Immunol 1995; 154: 1956-1963. 


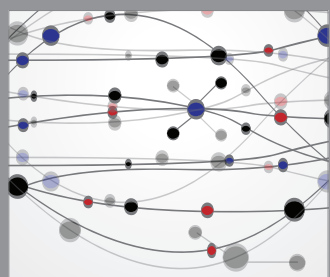

The Scientific World Journal
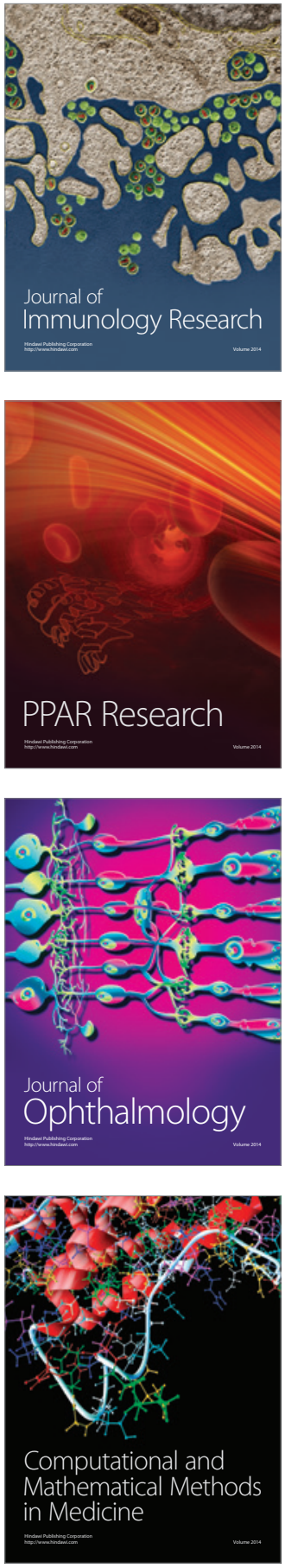

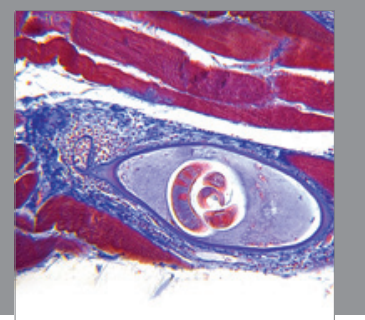

Gastroenterology

Research and Practice
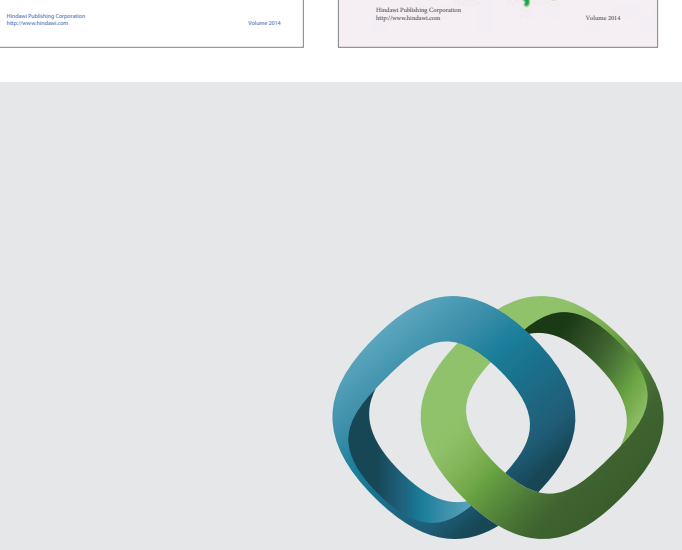

\section{Hindawi}

Submit your manuscripts at

http://www.hindawi.com
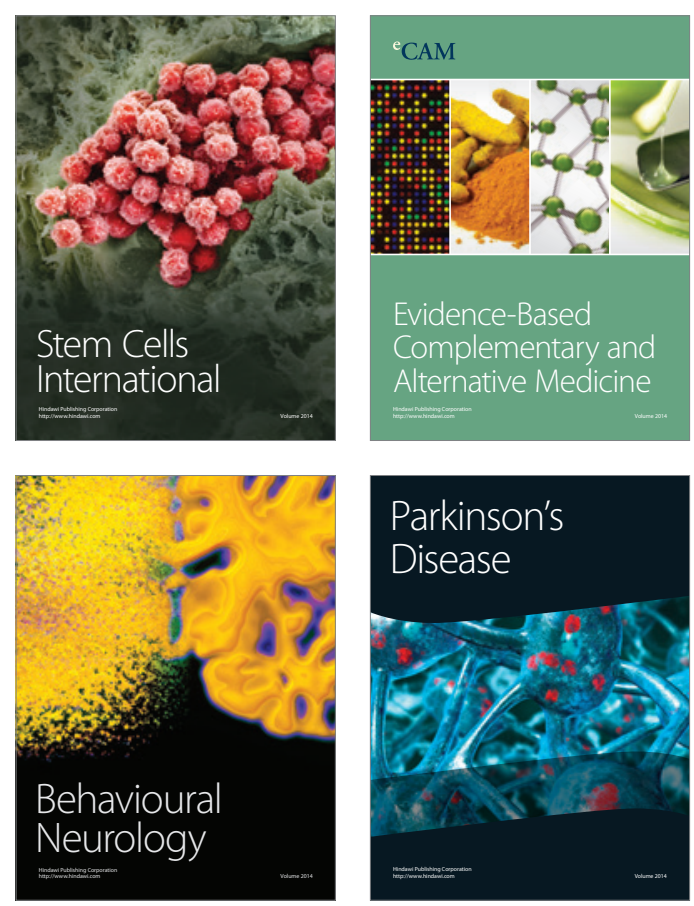

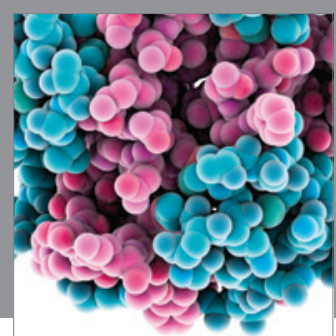

Journal of
Diabetes Research

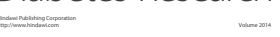

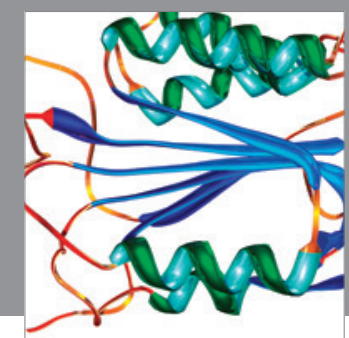

Disease Markers
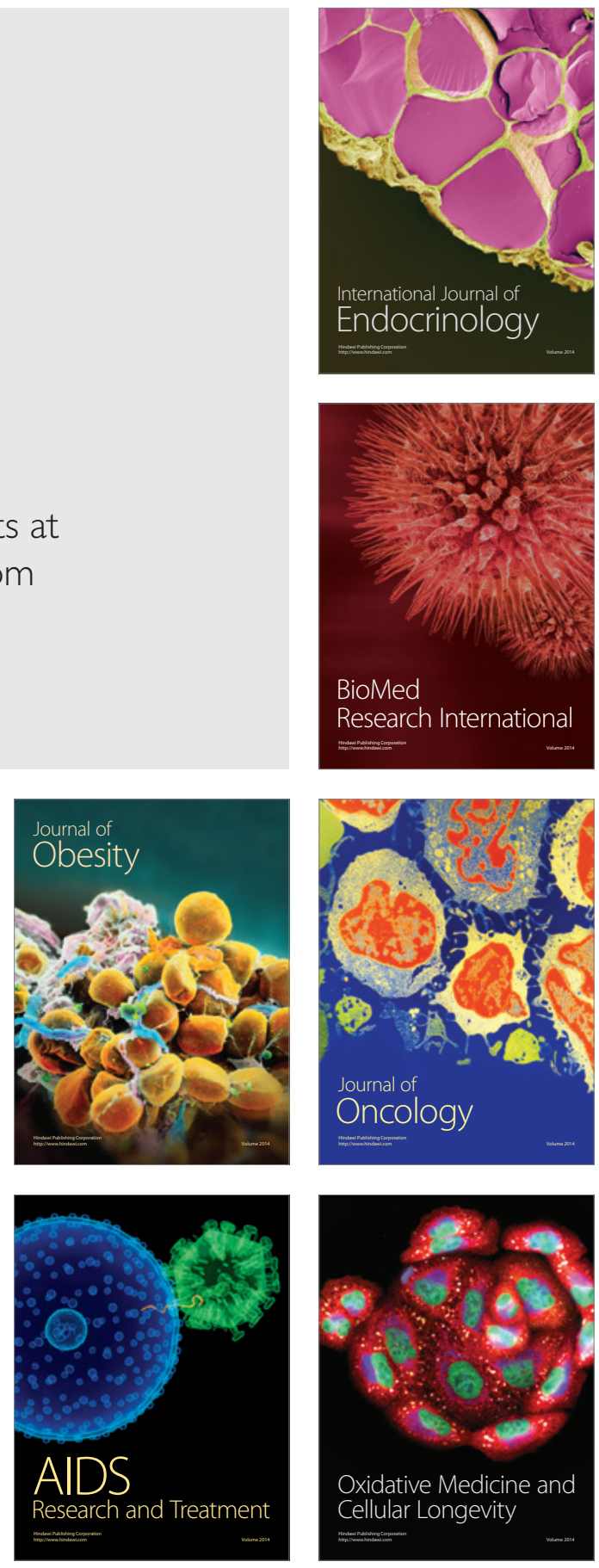